\title{
The Gulf Stream Voyage: Using Real Time Data in the Classroom
}

\author{
Liesl Hotaling \\ Center for Innovation in Engineering and Science Education \\ Stevens Institute of Technology
}

\begin{abstract}
The Gulf Stream Voyage is an Internet-based multidisciplinary project which utilizes both real time data and primary source materials to help guide students to discover the science and history of the Gulf Stream. There are several advantages of using real time data in the classroom including: the infusion of inquiry-based learning, fostering problem solving skills, addressing several learning styles, and student relevance.
\end{abstract}

\section{INTRODUCTION}

The Gulf Stream Voyage [1] is one example of an Internet-based, multidisciplinary project which utilizes both real time data and primary source materials to help guide students to discover the science and history of the Gulf Stream. Students investigate the current, how it affects the Atlantic Ocean and some of mankind's experiences dealing with the current. This voyage includes activities relevant for marine science, earth science, chemistry, physics, biology, math, history and language arts classrooms. All of the lessons may be easily used in today's technology-enhanced classroom.

Studies have shown that the use of engaging, authentic curricula that include relevant uses of the Internet by teachers and students improve student achievement in core subjects, and can promote higher order thinking, critical analysis, collaboration, and problem solving.

\section{REAL TIME DATA AND THE INTERNET}

\section{A. How the Internet is effectively used in classrooms}

Since 1994, the Center for Innovation in Engineering and Science Education (CIESE), located at Stevens Institute of Techonology has worked to promote the use of Internet resouces in K-12 science and mathematics education. As one of the first groups to experiment with Internet infusion, CIESE sought to position this technology in a way that would justify the time, resources and effort necessary to effectively use the technology. CIESE explored applications of the Internet and enhancements to student learning that could not be accomplished through books or any other conventional means.

In refining CIESE's position, potential applications of the Internet were judged by the criteria of "unique and compelling." In considering whether an Internet-based classroom activity met these criteria, we asked two questions: (1) Can these learning activities be accomplished in any other way? and, (2) do the educational outcomes justify the stillconsiderable effort teachers must invest to use the Internet effectively in the classroom?

Over the years, CIESE has identified five unique and compelling applications of the Internet for K-12 education:

- Use of real time data from governmental, scientific and commercial sources;

- Access to unique and primary source information;

- Telecollaborative projects using databases compiled by project participants;

- Student publishing on the web; and

- "Ask an Expert" - accessing topic experts through web sites and email.

Until the availability of the Internet in classrooms, students had to use limited and outdated data sets to learn about dymanic earth systems. For years, talented teachers have used "event-based" activities to interest students and tap current information on a topic, however access to real time data provides students with the most current information. Access to real time data also provides authenticity and investment in concepts being explored that no textbook or historical data could. Using real time data in the classroom engages students in the scientific process and in using technology in the same way that researchers do: analyzing real data, formulating and testing hypotheses, and refining their ideas to account for the evidence collected [2].

\section{B. Advantages to using real time data in classrooms}

There are several advantages to using real time data in the classroom including:

- infusion of inquiry based learning;

- fostering problem solving skills;

- addressing several learning styles;

- student relevance; and

- assisting ESL learners.

Inquiry based science and problem solving activities that incorporate the use of real world data are advocated by the National Council of Teachers of Mathematics (NCTM), the American Association for the Advancement of Science (AAAS), and the National Science Education Standards as a powerful "avenue through which students can increase their science and mathematics literacy." [3] 
In the National Assessment of Educational Progress (NAEP) Science findings of 2000, results reveal a statistically significant increase in scores of those students who downloaded and analyzed data. There also exists compelling evidence that this approach to science instruction can improve standardized test scores [4].

The use of Information Technology and the Internet in classrooms is compatible with a wide variety of learning styles. It also enables the use of a broad range of engaging learning activities. The flexibility of Information Technology allows us to present and understand information using text, images, animation and sound to overcome traditional learning difficulties [5].

Using computers and real time data in the classrooms engages students principally because they enjoy using computers in the classroom. The use of technology also fosters $21^{\text {st }}$ century workforce skills including digital age literacy, inventive thinking, effective communication and high productivity [6].

Technology integration has also proven valuable in English as a Second Language (ESL) classrooms. ESL students using computers and technology have displayed enhanced motivation, increased language proficiency, improved academic achievement and demonstrated higher level thinking skills [7].

Teachers trained effectively in the of use real time data in the classroom tend to:

- feel better prepared to teach problem-solving skills; spend less time lecturing;

- report an improved ability to teach complex concepts; are better able to conduct small group learning activities;

- can more easily implement cooperative learning approaches; and

- $\quad$ are more effective in managing diverse learning styles [8].

\section{PROJECT DESCRIPTION}

The Gulf Stream Voyage is an Internet-based multidisciplinary project which utilizes both real time data and primary source materials to enable students to discover the science and history of the Gulf Stream. Students investigate the Gulf Stream current, it's influence on the Atlantic Ocean and some of mankind's experiences dealing with the effects of the current. The Gulf Stream Voyage includes activities for marine science, earth science, chemistry, physics, biology, math, history and language arts classrooms. All of the activities can be easily integrated into today's technologyenhanced classroom.

The Gulf Stream Voyage project has been used in grades 6 - 14 classrooms across the country and has been used successfully in Adult Literacy classrooms, teaching users how to access and interpret real time oceanographic and satellite data, and how to use the information to solve real world problems.

The project lesson plans are divided into two sections; Core Lessons and Enrichment Lessons. The intention is for teachers and students to move through the Core Lessons to learn basic scientific and historic information about the Gulf Stream current. Once the basics are covered, then teachers and/or students can decide to work through a variety of Enrichment Lessons to build upon the core knowledge.

\section{A. Core lessons}

The Core Lessons section is comprised of three lessons that expose students to some of the science and history associated with the Gulf Stream current. The Core Lessons are:

- Map of the Gulf

- History of the Current

- The Current Today

In the first lesson, Map of the Gulf, students are challenged to create a concept map (graphic organizer) to depict the connections of various factors involved with the Gulf Stream current and its movement in the Atlantic Ocean. There are three levels of concept maps that teachers can chose from to best complement the student ability level in their classrooms. This lesson is intented to serve as a pre-test or assessment of prior knowledge before beginning the project, however the same concept maps can be created by students at the end of the project to serve as a post-test.

The second lesson, History of the Current, is an exercise in cooperative group learning. Teams of students are challenged to investigate the effects of the Gulf Stream on sailing ship travel, to research methods that were used in the past to determine the location of the Gulf Stream, and to report historical examples of the influence of the Gulf Stream on early American history and industry.

The Current Today is the third lesson in the Core section. The lesson employs the use of student cooperative working groups to solve a real world problem, namely to locate the Gulf Stream current in real time. Each student working group consists of three pairs of students. The first of pair of students is provided with Internet links to key National Oceanic and Atmospheric Administration (NOAA) coastal buoys that provide water temperature, wave height and meteorological data. A second pair of students is provided with Internet links to real time data as reported by ships currently traveling in the North Atlantic Ocean. This data includes:

- the location of the ships in real time;

- meteorological data in the vicinity of the ships;

- water temperature in the vicinity of the ship; and

- wave height in the vicinity of the ship.

A third pair of students is provided with Internet links to near real time satellite images mapping sea surface temperatures. Each pair of students is responsible for collecting specific information and answering questions pertaining to their 
assigned data source. The students then report back to their larger team group and combine all of the collected data to determine the current location of the Gulf Stream.

After completing the Core Lessons, students should be able to:

- use a graphic organizer to depict basic facts about the Gulf Stream current;

- discuss the history of the Gulf Stream as it pertains to early American history;

- describe effects of the Gulf Stream on ship travel;

- describe historical methods of determining the position of the Gulf Stream; and

- $\quad$ use real time data and modern methods to determine the current location of the Gulf Stream.

\section{B. Enrichment lessons}

The Enrichment Lessons section comprises six lessons that expose students to some of the effects the Gulf Stream current has on climate, weather, organisms, ship travel and history. The Enrichment Lessons include:

- Climate

- Biology

- Fishing

- $\quad$ The Amistad

- Drifters

- $\quad$ Ship Movement in the Gulf

The Enrichment Lesson on Climate leads students through a series of six links to various cities on either side of the Atlantic Ocean. The students must record the latitude and longitude of each city, local weather, and average climate conditions to determine if they are influenced by the Gulf Stream.

In the Biology lesson, students learn to obtain and interpret data about sea surface temperature and chlorophyll-a concentrations. Students learn to determine, in real time, the locations of concentrations of phytoplankton in the region of the Gulf Stream. Students are also challenged to investigate other regions of the ocean to look for patterns in distribution of phytoplankton.

Does the Gulf Stream have an effect fish distribution in the Atlantic Ocean? In the Fishing lesson, students partner together pretending to own an east coast fishing fleet with boats currently in Cape Hatteras, North Carolina, Boston, Massachusetts, and Halifax, Nova Scotia. The company only has the resources to send one boat out to fish for yellowfin tuna. The students must first collect background information about yellowfin tuna including normal geographic range, normal temperature range and optimal temperature range for the fish. Students also collect near real time satellite imagery of the location of the Gulf Stream and real time buoy data. Students then predict the best location to dispatch their fishing boat to in order to hunt for yellowfin tuna. The lesson is intended to provide students with a general understanding of data collected on sea surface temperature, and how it is used by a variety of professions, not just research scientists.
On the morning of August 26, 1839, the Amistad appeared off the tip of Long Island, New York. The Amistad was a sailing vessel involved with slave trade, running between the Caribbean and the United States. The unscheduled appearance of the boat was not the only unusual happening. In The Amistad lesson, students learn about these important historical events, and the influence of the Gulf Stream current on the path of the vessel.

Annually, before the onset of hurricane season, a drifting buoy array is deployed into waters of the tropical Atlantic. This array of drifting buoys provides weather forecasters with surface meteorological data in the region of hurricane development. Ocean weather data is usually collected by a network of commercial ships crossing the Atlantic. However, in times of rough seas or hurricanes, the commercial ships must deviate from their original course to protect the crew, ship and cargo. The data collected from the buoys, combined with satellite data and information reported by special hurricane research aircraft, are used by meteorologists to predict the path of hurricanes. While engaged in the Drifters lesson, students will access the drifting buoy database via the Internet. Students will:

- $\quad$ check that the buoys are still reporting data;

- monitor the various paths of the buoys;

- determine the influence of the Gulf Stream current on the drifters' trajectories.

In the final Enrichment Lesson, Ship Movement in the Gulf Stream, students access near real time velocity data for the Gulf Stream current. The students are then given various locations and ship headings to determine if the velocity of the current would create a noticable difference to the resulting path of the ship.

\section{Project assessment}

There are two lessons in the Gulf Stream Voyage project used for student assessment. The aforementioned concept map lesson contained in the Core Lessons, and the How Do Currents Affect You? Lesson. In this lesson, students determine which current flows past the coast where they live and whether it is a cold or warm water current. The students are challenged to determine how they think the current affects their lives. Based on all of the information aquired in the unit, students must prepare a "Shore Guide." The "Shore Guide" must contain information about the climate in the area, biological life found near the coast and the possibility of the water being warm for a beach outing.

\section{EVALUATION}

\section{A. Purpose and goals}

In the spring of 2003, an evaluation of the Gulf Stream Voyage project was conducted. The purpose of the formative evaluation was to improve the Gulf Stream Voyage project educational materials and project web site. During the evaluation, information was gathered about the use and 
usability of the educational materials and web site by classroom teachers. The main questions for this formative evaluation were:

- How are teachers using the Gulf Stream Voyage web site?

- How can the web site be improved?

- Do teachers understand real time data?

- Are teachers using the real time data?

- Are the lessons and other materials on the web site supporting and enhancing what teachers do in the classroom?

\section{B. Methods and procedures}

To gather the data needed to answer the evaluation questions, CIESE recruited middle and high school teachers to participate in the evaluation process. The teachers were asked to visit and review the project web site, use the educational materials and project web site with their students, and keep a journal of their experiences using the materials. Face-to-face interviews were conducted with three teachers and telephone interviews with seven teachers. Each interview consisted of:

- a discussion about the uses of the web-based educational materials in the classroom by the teacher and his/her students;

- a review of any materials brought to the interview by the teachers;

- $\quad$ an assessment by the teachers of each of the features of the web site to determine what teachers had used and what they liked/disliked.

Ten in-depth teacher interviews were the basis for the evaluation report. A small sample of evaluation questions and responses are contained in the following tables.

TABLE 1. Responses to Question \#12 ( $\mathrm{n}=10)$

How much do you agree or disagree with each statement below?

\begin{tabular}{|l|c|c|c|}
\hline Question & Agreed & Disagreed & Undecided \\
\hline $\begin{array}{l}\text { The web site provided } \\
\text { lessons that I could use } \\
\text { with my students. }\end{array}$ & $100 \%$ & $0 \%$ & $0 \%$ \\
\hline $\begin{array}{l}\text { I found the web site } \\
\text { lessons easy to integrate } \\
\text { into my curriculum. }\end{array}$ & $90 \%$ & $0 \%$ & $10 \%$ \\
\hline $\begin{array}{l}\text { I could have used more } \\
\text { support on the use of the } \\
\text { web site. }\end{array}$ & $10 \%$ & $80 \%$ & $10 \%$ \\
\hline
\end{tabular}

TABLE 2. Responses to Question \#13 ( $=10)$

What did you like most about the web site?

The most common response (50\%) was that the web site used real time data or had real-world applications.

"It made the Gulf Stream more tangible, that it has substance, and isn't just a current of warm water. The site related the Gulf Stream to fishing, whaling, transportation, and made it more real; it's not just a line on a map.'

"It's on the Internet, easily accessible, you just click and go."

"The activities are ready to go. Students just need a little bit of background/preparatory work. Also, the completeness of the lessons."

"That it's student centered; they're doing a lot of learning on their own, and I'm not teaching. They were interested, there was high student interest; it's motivational for students."

"The interdisciplinary nature of the site".

"There are colorful pictures for visual learners".

TABLE 3. Responses to Question \# 15 ( $\mathrm{n}=10)$

Do you think you will use the web site next year with students?

\begin{tabular}{l|r} 
Yes $-90 \%$ & No $-10 \%$ \\
\hline
\end{tabular}

\section{Evaluation conclusions}

Due to the wide range of student ability levels, prior science knowledge, and teacher competency levels, a wide range of responses were received on the use of the Gulf Stream Voyage project web site.

Generally, the middle and high school teachers were familiar with the science content and they were able to adapt and use the web site as planned by the designers. Many, but not all were able to keep their students on track. Overall, the participating teachers were enthused about the Gulf Stream Voyage project and were looking forward to using it during subsequent school years.

Most of the middle and high school teachers were able to access the real time data and solve the problems presented in the lessons [9].

\section{CONCLUSION}

The Internet is an important tool that teachers are using in classrooms all over the world. The integration of the Internet into classroom lessons promotes student engagement in authentic, and encouraged critical thinking, problem-solving, teamwork and increases self-motivated learning.

Providing access to real time data activities provides opportunites for students to analyze and assimilate knowledge in a meaningful way. Educational research indicates that real time data provides a greater sense of authenticity and purpose than textbooks or historical data sets. Using real time data in classrooms engages students because they participate in the same scientific process as professional scientists.

The formative evaluation conducted on the lessons contained within the Gulf Stream Voyage project served as positive reinforcement of the benefits to using real time data and technology in classrooms contained within educational research literature. 
The Gulf Stream Voyage project is an example of a real time data project that has been successfully implemented in classrooms. The use of formal evaluation of educational products is essential to assess the quality and useability of the materials. The results of the Gulf Stream Voyage formative evaluation justify increased usage of real time data projects in classrooms.

Since the posting of real time data on publicly accessible web sites is prevalent within both the ocean science and commercial maritime communities (e.g. the proposed data streams from Integrated Ocean Observing System - IOOS or data streams from IOOS or Ocean Research Interactive Observatory Networks/Ocean Observatories Initiative ORION/OOI), this subject matter is particularly appropriate for teaching through internet based classroom projects.

\section{ACKNOWLEDGMENT}

The author would like to thank Chris Parsons of WordCraft for all of her work in leading the Gulf Stream Voyage evaluation process.

The author also gratefully acknowledges the contributions of all the teachers and students who have implemented the Gulf Stream Voyage in their classrooms to advance their own knowledge of ocean circulation and the Gulf Stream Voyage, and to collectively advance the research on the impact of using real time data in classrooms.

\section{REFERENCES}

[1] Gulf Stream Voyage (Educational web site). http:/www.k12science.org/curriculum/gulfstream/index.s $\underline{\mathrm{html}}$

[2] E. McGrath, "Is it unique and compelling?," Momentum Magazine, September/October 2001.

[3] Eisenhower Regional Consortia for Mathematics and Science Education: Eisenhower National Clearinghouse (ENC); U.S. Department of Education (DED), Office of Educational Research and Improvement. "Promising Practices in Mathematics and Science Education 1995: a collection o promising educational programs and practices from the Eisenhower Mathematics and Science Regional Consortia," Reform in Math and Science Education, Eisenhower National Clearinghouse, U.S. Department of Education, 1995.

[4] C. O’Sullivan, M. Lauko, W. Grigg, J. Qian, and J. Zhang, "The Nation's Report Card: Science 2000," National Center for Education Statistics, January 2003.

[5] B. Klicek, M. Susac, "Toward integrated and revised learning styles supported by web and multimedia technologies," The 8th Annual Conference of the
European Learning Styles Information Network (ELSIN), University of Hull, Hull, England, Juy 2003.

[6] J. Bransford, A. Brown, and R. Cocking, How People Learn, National Academy Press, Washington D.C., 1999.

[7] M. Warschauer, H. Shetzer, and C. Meloni, Internet for English Teaching, Teachers of English to Speakers of other Languages, Inc. (TESOL) Publications, August, 2000 .

[8] M. Yepes-Baraya, "Minority student retention and academic acheivement," Alliance+ Mid-Point Evaluation Report, January 2003.

[9] C. Parsons, "Gulf Stream Voyage web site 2003 formative evaluation report," 2003 (unpublished). 